\title{
The effect of pozzolan addition on the physical and mechanical properties of lime mortar
}

\author{
Przemystaw Brzyski ${ }^{1, *}$ \\ ${ }^{1}$ Lublin University of Technology, Faculty of Civil Engineering and Architecture, Department of \\ Construction, Nadbystrzycka str. 40, 20-618 Lublin, Poland
}

\begin{abstract}
Hydrated lime, due to its life cycle (return to the natural form as a result of binding and hardening) shows a positive ecological aspect. The binder is often used in building materials based on plant components due to the high alkaline reaction and low diffusion resistance, as well as in mortars and plasters. However, it is an air binder with low strength parameters and the process of its binding and hardening is long-lasting. One of the ways to accelerate the binding processes and also to increase the strength of the binder is the use of additives in the form of pozzolanic materials which react with calcium hydroxide and form compounds with hydraulic properties. These are natural materials or industrial waste, so they do not affect the environmental impact of lime binder. The article presents the influence of the addition of pozzolan (three types) in various weight amounts, on the strength properties of mortars, their absorbability and capillary rise (presented as water absorption coefficient). The influence of pozzolan presence on workability of fresh mortars - their consistency was also checked.
\end{abstract}

\section{Introduction}

Hydrated lime, as well as cement, is a basic component of mortars. It is an air binder with low strength parameters. However, it is characterized by high vapour permeability and resistance to biological corrosion due to high $\mathrm{pH}$. These properties are used, for example, in composites based on lime binder and hemp shives (organic material) $[1,2]$ or in mortars with lightweight, organic fillers [3]. This binder, due to its life cycle (return to the natural form as a result of binding and hardening) shows a positive ecological aspect.

In ancient times, the Romans were working on lime modification techniques using them extensively in building construction as mortar and as a binder in construction materials. Carbonation process was accelerated for example by the addition of new fig wine to the mix. Thus, the fermentation of wine, and therefore emitting carbon dioxide in the structure of the mortar accelerated transformation of a calcium hydroxide to calcium carbonate [4]. They also used mineral additives in the form of local materials - volcanic ash, which are classified as natural pozzolans. The name 'pozzolan' comes from the village Puzzolo, located at volcanic areas. Pozzolans are fine-grained materials consisting mainly of silica in a reactive form. Pozzolan is not a binding material, but in the presence of moisture,

\footnotetext{
*Corresponding author: p.brzyski@pollub.pl
} 
it chemically reacts with calcium hydroxide, forming compounds that have binding and hydraulic properties.

References provide many test results on mineral binders modified by pozzolanic materials. Pozzolan, widely used in research on the modification of binders, is silica fly ash which is an industrial waste [5, 6]. Fly ash is also used in production of geopolymer binders [7]. Similarly, the highly reactive pozzolan - silica fume is often used as replacement for part of the clinker in the high value concrete $[8,9]$. Among used pozzolans (natural or synthetic) there are also: zeolite, for example in the high value concrete [10], modified lime binder [11] or also in asphalt mixes [12]. Another pozzolanic material used widely as an additive for binder and concrete is metakaolinite [13]. The effect of adding metakaolinite to lime mortar in various proportions of aggregate : binder has also been studied [14].

Improving the strength parameters and increasing the resistance to water through the use of additives and admixtures may contribute to the extension of the use of lime binders.

The article presents the analysis of the influence of the pozzolanic additives metakaolinite, microsilica and natural zeolite used as partial replacement of hydrated lime in different quantities, on mechanical and physical properties of lime mortar. It also examines the influence of these materials on the consistency of the fresh mortar mix.

\section{Materials and methods}

\subsection{Materials and recipes}

Mortars were made of hydrated lime, modified by pozzolanic additives in various amounts. Three additives were used in various combinations: metakaolinite, microsilica, and natural zeolite. Metakaolin is a highly reactive pozzolanic material which is formed in the kaoline clay calcination process in controlled temperature conditions of around $600^{\circ} \mathrm{C}-850^{\circ} \mathrm{C}$. Its main ingredient is hydrated aluminum silicate $\mathrm{Al}_{2} \mathrm{Si}_{2} \mathrm{O}_{5}(\mathrm{OH})_{4}$. Silica fume (microsilica) is obtained as waste in the production of silica and ferro-silica alloy. During the production at high temperature, $\mathrm{SiO}$ fumes are formed at a low ambient temperature oxidize and condensed in the form of fine spherical particles of non-crystalline silica $\left(\mathrm{SiO}_{2}\right)$. Zeolite is a natural mineral from the group of alumino-silicate minerals with different chemical composition, properties and crystal forms. The basis is hydrated alkaline aluminosilicate called clinoptilolite (in the amount of $84 \%$ of the mineral composition), the main chemical constituent of the reactive silica $\mathrm{SiO}_{2}(61-71.3 \%)$ and aluminum oxide $\mathrm{Al}_{2} \mathrm{O}_{3}(11.15-13.2 \%)$. Silica sand was used as an aggregate in accordance with EN 196-1 standard to avoid the influence of fraction randomness on results. The main objective of the study was to determine the influence of substitutes on the properties of lime mortar. Depending on the recipe, addition of $10 \%, 20 \%, 30 \%$ of pozzolans as partial replacement of hydrated lime was used. Table 1 shows the formulation of each compound in proportions by weight. Reference mortar is designated as $L M$, mortar with the addition of metakaoline as $M K$, silica fume as $S F$ and zeolite as $Z$. 
Table 1. Compositions of mortars (weight proportions).

\begin{tabular}{|c|c|c|c|c|c|}
\hline Symbol & Hydrated lime & Metakaolinite & Silica fume & $\begin{array}{c}\text { Natural } \\
\text { zeolite }\end{array}$ & $\begin{array}{c}\text { Binder: sand: } \\
\text { water }\end{array}$ \\
\hline LM & $100 \%$ & - & - & - & $1: 3: 0.8$ \\
\hline MK10 & $90 \%$ & $10 \%$ & - & - & $1: 3: 0.8$ \\
\hline MK20 & $80 \%$ & $20 \%$ & - & - & $1: 3: 0.8$ \\
\hline MK30 & $70 \%$ & $30 \%$ & - & - & $1: 3: 0.8$ \\
\hline SF10 & $90 \%$ & - & $10 \%$ & - & $1: 3: 0.8$ \\
\hline SF20 & $80 \%$ & - & $20 \%$ & - & $1: 3: 0.8$ \\
\hline SF30 & $70 \%$ & - & $30 \%$ & - & $1: 3: 0.8$ \\
\hline Z10 & $90 \%$ & - & - & $10 \%$ & $1: 3: 0.8$ \\
\hline Z20 & - & - & - & $20 \%$ & $1: 3: 0.8$ \\
\hline Z30 & - & - & - & $30 \%$ & $1: 3: 0.8$ \\
\hline
\end{tabular}

\subsection{Methods}

\subsubsection{Preparation of the samples}

First, to obtain a homogeneous binding material, hydrated lime was mixed with additives. Then the silica sand was added and mixed together. Finally, water was added. The mixing was carried out in an automatic mortar mixer. The mixing time was 90 seconds. Fresh mortars were molded in a three-part mold for trabeculars with dimensions of $40 \times 40 \times 160 \mathrm{~mm}$. For the first five days after the cast, the samples were placed in the molds in relative humidity of approx. $95 \pm 5 \%$. After 5 days, the samples were disbanded and left under humidity of $95 \pm 5 \%$ for further 2 days. Then, for 21 days the samples were matured in conditions of relative humidity of $60 \pm 5 \%$ and a temperature of $20 \pm 2{ }^{\circ} \mathrm{C}$ in accordance with EN 1015-2 standard. The only Single samples (without any additives) needed seven days before the molds were removed.

\subsubsection{Consistency}

After mixing, the measurement of the consistency of the fresh mortar has commenced by two methods:

- By flow table according to EN 1015-3 standard. According to this method, the size of the fresh mortar propagation is determined by measuring the average diameter of the sample of fresh mortar placed on the flow table disc by a mold in the shape of a truncated cone and subjecting it to vertical shock by raising and free dropping of the flow table from a specified height.

- By plunger penetration according to EN 1015-4 standard. According to this method, the size of the fresh mortar propagation is determined by the vertical penetration of the indenter while free dropping to a predetermined depth in the sample of the fresh mortar.

\subsubsection{Flexural and compressive strength}

The flexural strength was determined in accordance with EN 1015-11:2001 standard using MTS 810 press with the maximum range of the load of $100 \mathrm{kN}$ on trabeculars with dimensions of $40 \times 40 \times 160 \mathrm{~mm}$, causing the movement of the head loading of $0.2 \mathrm{~mm} / \mathrm{min}$. The compressive strength of the hardened mortars was determined using Controls press on the broken half samples of $40 \times 40 \times 160 \mathrm{~mm}$. The increase in strength was defined differently for various percentages of additive content - between $50 \mathrm{~N} / \mathrm{s}$ and $400 \mathrm{~N} / \mathrm{s}$. 
The study was completed after reaching the maximum compressive force equivalent to the destruction of the sample. The test was conducted on 6 samples of each recipe.

\subsubsection{Mass absorptivity}

The absorbability test was carried out according to EN 13755 standard on three $40 \times 40 \times 160 \mathrm{~mm}$ samples which were previously dried to a constant mass. Mass growth of samples soaked with water was controlled daily, until the state of complete saturation with water. The state of maximum saturation with water was reached after 3 days of testing.

\subsubsection{Water absorption coefficient}

The test was carried out according to EN 1015-18 standard. Samples with dimensions of $40 \times 40 \times 80 \mathrm{~mm}$, dried to a constant mass, were prepared for the tests. Four vertical surfaces, in relation to the water surface, were covered with bituminous mass. The samples were placed in water to a depth of $10 \mathrm{~mm}$. The samples were set at distances to provide access to water of the soaked surface. To prevent evaporation of water from the vessel and the samples, the vessel was covered with foil. Weight gain was measured after 10 and 90 minutes after immersion.

\section{Results and discussion}

\subsection{Consistency}

The results of the consistency measured by flow table are presented in Figure 1 and the results of the consistency measured by plunger penetration are shown in Figure 2.

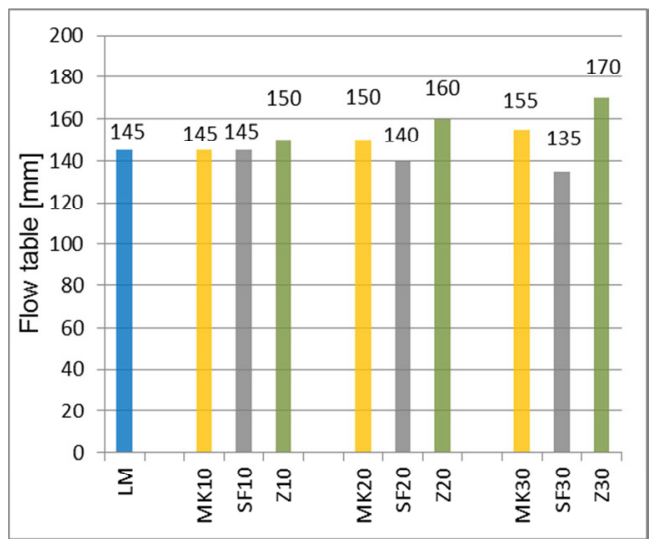

Fig. 1. Consistency of fresh mixes measured by flow table.

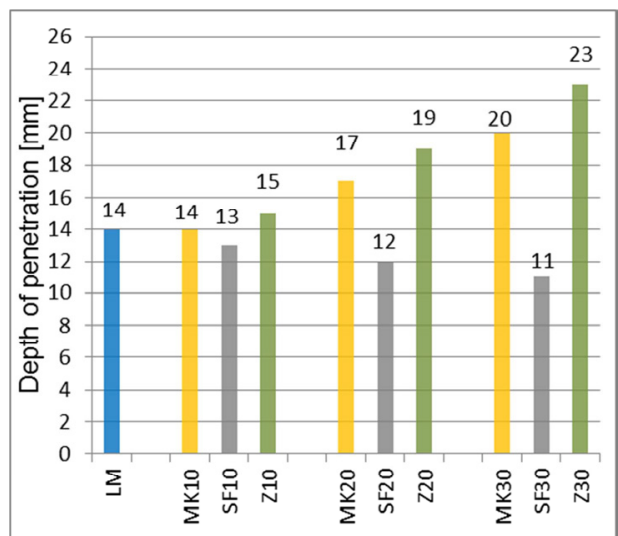

Fig. 2. Consistency of fresh mixes measured by plunger penetration.

Increasing the amount of pozzolans and decreasing the amount of hydrated lime caused an increase in diameter of flow and depth of penetration of the fresh mortar with the exception of silica fume, which contributed to the opposite effect. The kind of additive and its specific surface area had a significant impact on the consistency. The kind of mixture had an even greater effect, and gave it plasticity characteristics. Only the silica fume in the amount of $30 \%$ by weight of the binder caused the mortar to obtain thick consistency. $(135 \mathrm{~mm})$. Mortars which contained microsilica showed significant viscosity and poor workability. Laying and compacting the mixtures with silica fume in the three-part molds was difficult. This is due to the high fragmentation of microsilica and its largest specific 
surface area of the additives used. Other recipes are between 140 and $170 \mathrm{~mm}$, so it is considered as plastic consistency. These fresh mortars, in turn, showed better properties in terms of workability. The largest diameter of the spread was observed in the case of mortar with zeolite (150 to $170 \mathrm{~mm}$ ). These materials, in turn, are characterized by the lowest specific surface area of the ones used, which resulted in the smallest demand for water. Analogous relations were observed in the consistency test using a plunger penetration.

\subsection{Flexural strength}

The results of the flexural strength are shown in Figure 3. Error bars mean confidence intervals for the average.

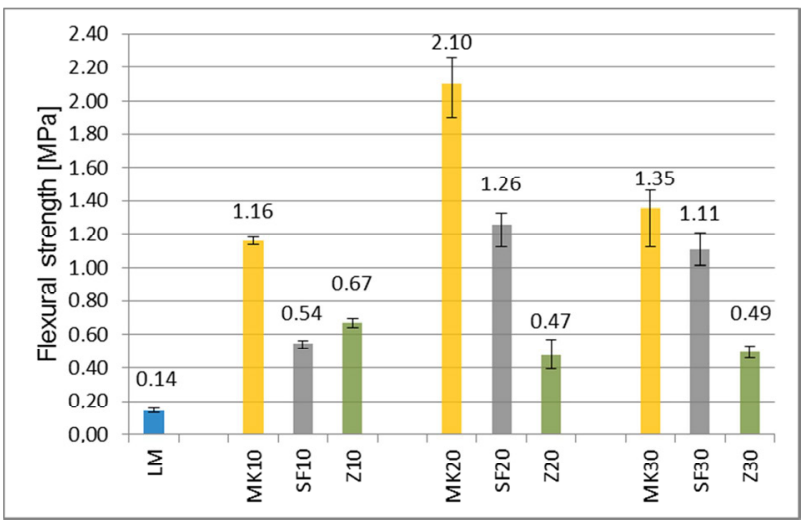

Fig 3. Flexural strength of tested mortars.

The type of replacer and the mixing ratio of the binder had a significant influence on the change of the 28-day strength of mortars in relation to the reference mortar. The addition of metakaolinite preferably caused an increase in flexural strength. The addition of metakaolinite in the amount of $10 \%$ resulted in obtaining almost twice as much of the strength as when adding the same amount of microsilica or zeolite. Increasing the amount of metakaolinite to $20 \%$ by weight of the binder resulted in doubling the strength of the MK10 sample. In turn, further increasing the amount of this pozzolan is not sensible because of the strength test parameter, since the strength of MK30 was reduced by nearly $37 \%$ of MK20. Similar observations are described in the literature [14]. The SF samples obtained almost half the flexural strength of MK mortar with the addition of $10 \%$ and $20 \%$. In turn, the addition of zeolite proved to be most effective in the amount of $10 \%$ by weight of the binder. It is possible that the effect of adding larger quantities of these pozzolans prove to be beneficial after a period longer than 28 days of maturation.

\subsection{Compressive strength}

The results of the compressive strength test are shown in Figure 4. Error bars mean confidence intervals for the average.

In the case of the compressive strength, the addition of metakaolinite and microsilica were most effective. The addition of the zeolite caused an increase in strength in proportion to the amount of used material. The compressive strength increased by $1.21 \mathrm{MPa}, 2.3 \mathrm{MPa}$ and $3.28 \mathrm{MPa}$. Individual mortars behaved differently under load. In samples with the addition of microsilica that are characterized by high plasticity, the process of loading lasted the longest, despite the same loading speed of other mortars. 


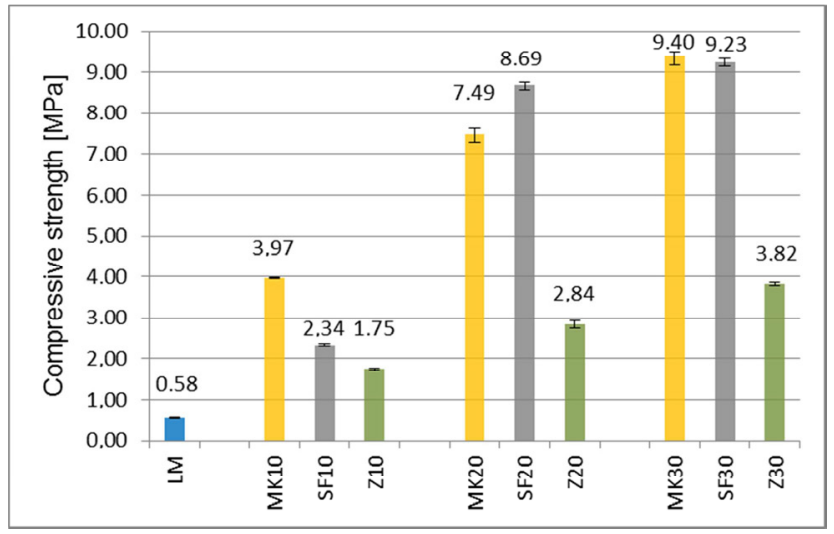

Fig. 4. Compressive strength of tested mortars.

Visually, these samples were slowly being destroyed, but still resisted the loading force. Samples with metakaolinite demonstrated higher stiffness and load increment and in time turned into liquid samples, such as those assumed, which resulted in faster and more pronounced destruction. The addition of metakaolinite in the amount of $10 \%$ resulted in significantly better results than for microsilica because MK10 mortar strength was almost two times higher than SF10. However, when comparing the mortar with the addition of these materials in the amount of $20 \%$, we can see a clear change - SF20 received a higher strength of 1.23 MPa than MK20.

Comparing both strengths it can be noticed that microsilica affects the growth of compressive strength much more than flexural strength. The addition of pozzolanic materials also raises the early strength of lime mortar. According to the literature [15], a $20 \%$ addition of metakaolinite increased compressive strength by $0.5 \mathrm{MPa}$, whereas microsilica by $1.5 \mathrm{MPa}$ after 5 days of maturation.

\subsection{Mass absorptivity}

The results of mass absorptivity are shown in Figure 5. Error bars mean confidence intervals for the average.

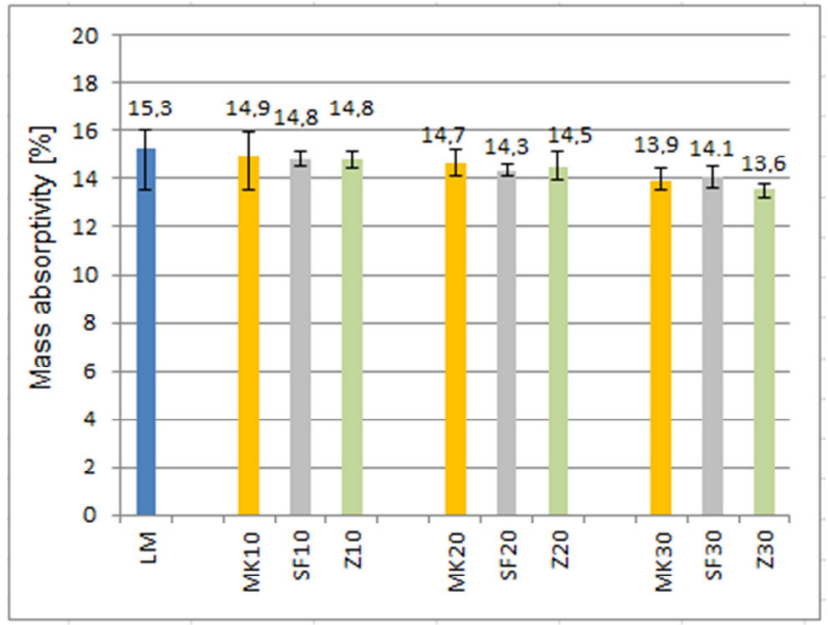

Fig. 5. Mass absorptivity of tested mortars. 
Mass absorptivity of mortars ranges from 13.6 to $15.3 \%$. Lime is a hygroscopic binder, showing the ability to quickly absorb moisture. The presence of pozzolan in the mortars resulted in the formation of hydraulic compounds, which caused the increase of the seal and thus the reduction of the absorbability. With the increase of additives content in the mortar, its absorbability decreases. Comparing the effect of different types of pozzolans on reducing water absorption by weight, it is difficult to determine the relationship. Partial replacement of air lime with each additives used in the amount of $10 \%$ had a similar effect (coefficient of 14.8\%-14.9\%). Increasing the amount of pozzolans led to larger differences in results depending on the kind of additive used. The lowest absorbability $(13.6 \%)$ is showed by the mortar containing 30\% zeolite (by binder weight). By partially replacing the lime with pozzolanic materials, it was possible to reduce the absorbability of the standard mortar by 0.4 to $1.7 \%$.

\subsection{Water absorption coefficient}

The results of water absorption coefficient are shown in Figure 6. Error bars mean confidence intervals for the average.

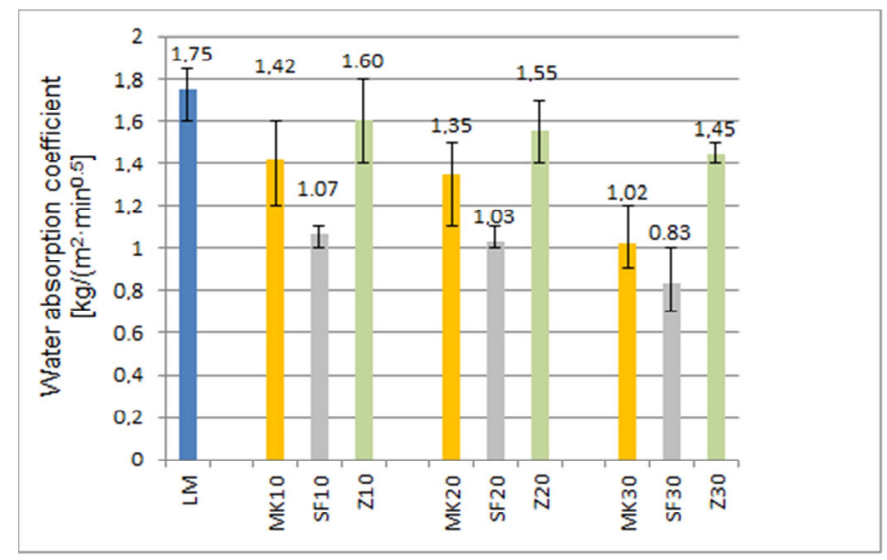

Fig. 6. Water absorption coefficient of tested mortars.

Water absorption coefficient of mortars ranges from 0.85 to $1.6 \mathrm{~kg} /\left(\mathrm{m}^{2} \cdot \mathrm{min}^{0.5}\right)$. The general observation is the decrease in the value of the water absorption coefficient along with the increase of the pozzolana content in the mortar. It is related to obtaining a greater tightness of the mortar after the pozzolan reaction.

The highest water absorption coefficient, i.e. the highest capillary water capability, was represented by mortars with the addition of zeolite. It is different in the case of weight absorption, where, for example, mortar with 30\% zeolite showed the lowest absorbability. The lowest values, in turn, were demonstrated by mortar samples with the addition of microsilica, which, owing to the presence of small fractions, caused the most effective sealing of the structure.

Partial replacement of hydrated lime with pozzolans reduced the water absorption coefficient by $5-10 \%$ in the case of metakaolinite, $6-11 \%$ in the case of zeolite and by $14-20 \%$ in the case of microsilica, respectively. 


\section{Conclusions}

Each of the substitutes used affected the improvement of mechanical properties of lime mortar because of the low strength of the model mortar based only on the air binder hydrated lime. The addition of pozzolans resulted in the formation of hydraulic compounds, improving the strength of the mortars. As the content of pozzolanic material increases, the mortar strength parameters increase. The least effective substitute for lime was natural zeolite. Mortars with this pozzolana reached the lowest strength (flexural strength of $0.49 \div 0.67 \mathrm{MPa}$ and compressive strength of $1.75 \div 3.82 \mathrm{MPa})$. In the case of flexural strength, metakaolinite was the most effective, in particular in the amount of $20 \%$ $(2.1 \mathrm{MPa})$. In the case of compressive strength, the addition of both metakaolinite and microsilica has resulted in a high increase in compressive strength. In the case of the addition of the lowest amount (10\%), metakaolinite was the most effective. The presence of pozzolan also resulted in a decrease in mass absorptivity and water absorption coefficient of tested mortars. Together with the increase in pozzolan content, these parameters were reduced. The lowest absorptivity was caused by the presence of zeolite in the amount of $30 \%$ and it was less than the mass absorptivity of the reference sample by $1.7 \%$. In turn, the lowest water absorption coefficient was demonstrated by samples containing microsilica, regardless of its amount. The consistency of fresh mortar depends on the amount of pozzolana. As the content of pozzolana increases, the diameter of the flow increases. The reverse is the case with the addition of microsilica, because it is characterized by greater water demand than hydrated lime. The tendency to change consistency is comparable in both test methods. The research presented in this work is continued in other aspects to demonstrate the possibility of wider use of binders other than Portland cement.

\section{References}

1. P. Brzyski, D. Barnat-Hunek, Z.Suchorab, G. Lagod, Materials 10, 5 (2017)

2. D. Barnat-Hunek, P. Smarzewski, P. Brzyski, J Nat Fibers 14, 5 (2017)

3. D. Barnat-Hunek, R. Siddique, G. Lagod, Constr Build Mater 155 (2017)

4. E. Osiecka, Wapno w budownictwie, Cracow (2006)

5. S. Alahrache, F. Winnefeld, J. B. Champenois, F. Hesselbarth, B. Lothenbach, Cement Concrete Comp 66 (2016)

6. D. Gazdič, K. Kulísek, M. Fridrichová, K. Dvořák, Procedia Eng 172 (2017)

7. A. Mehta, R. Siddique, BP. Singh, S. Aggoun, G. Lagod, D. Barnat-Hunek, Constr Build Mater 150 (2017)

8. S. Mahmoud Motahari Karein, A.A. Ramezanianpour, T. Ebadi, S. Isapour, M. Karakouzian, Constr Build Mater 157 (2017)

9. D. Rezaei-Ochbelagh, S. Azimkhani, H. Gasemzadeh Mosavinejad, Ann Nuc Energy 45 (2012)

10. T. Markiv, K. Sobol, M. Franus, W. Franus, Arch Civ Mech Eng 16 (2016)

11. B. Liguori, D. Caputo, F. Iucolano, Constr Build Mater 77 (2015)

12. A. Woszuk, A. Zofka, L. Bandura, W. Franus, Constr Build Mater 139 (2017)

13. R. Siddique, J. Klaus, Appl Clay Sci 43 (2009)

14. A. Gameiro, A. Santos Silva, P. Faria, J. Grilo, T. Branco, R. Veiga, A. Velosa, Cement Concrete Comp 45 (2014)

15. P. Łukowski, Materiały Budowlane 458/10 (2010) 